\title{
TRENDS IN THE EVOLUTION OF REGIONAL DISPARITIES OF ONCOLOGICAL MORTALITY IN ROMANIA
}

\author{
DOI: https://doi.org/10.18509/GBP210433n \\ UDC: 311.21:332.1.053.2]:616-006:314.14(498)"2008/2016"
}

\author{
Iulia Daniela Nedelcu ${ }^{1}$, \\ Adrian Gabriel Simion ${ }^{1,2}$ \\ Daniel Peptenatu', \\ ${ }^{1}$ University of Bucharest - Faculty of Geography, Bucharest, Romania. \\ ${ }^{2}$ Research Centre for Integrated Analysis and Territorial Management, Bucharest, Romania
}

\begin{abstract}
Cancer has been considered one of the most important problems globally, when it comes to the disease of the population, being ranked 2nd in the world after cardiovascular disease. According to international databases, such as the WHO, at European level, 25\% of new cancer cases are registered globally, approximately 3.9 million cases occur annually and approximately 1.7 million deaths. Cancer is also responsible for about $20 \%$ of all deaths annually. Most deaths are caused by lung cancer (C30 - C39), colorectal cancer (C15 - C26), breast cancer (C50) and pancreatic cancer (C15 - C26). In this material we want to present the situation of oncological mortality in Romania for the period 2008-2016, more precisely the identification of geographical areas with extreme values. This analysis starts from the medical database provided by the Romanian Ministry of Health on the incidence of cancer, starting with 2008, immediately after Romania's accession to the European Union, when the centralization of data in a unitary system was implemented. Data on oncological mortality are processed and then reported at the level of the territorial administrative unit in order to perform statistical analyzes and perform spatial models using GIS methods.
\end{abstract}

Keywords: cancer, oncological mortality, GIS, spatial distribution.

\section{INTRODUCTION}

According to the World Health Organization, cancer is one of the leading causes of disease in the global population, but also a major cause of mortality, in 2018 there were over 9.6 million deaths globally, 1 in 6 deaths are produces due to cancer. [1] Over time, numerous specialized studies have addressed the spatial dimension of cancer either in an attempt to find a closer link between the geographical distribution and the appearance of cancer cases, or to develop public policies with specific, regional location. [2], [3], [4], [5]. An important moment in the development of new methods and techniques for analyzing medical data, either statistical or imaging, is the use of GIS technology on a large scale. This technology allows first of all the processing of a immense volume of data according to the software specifications.

The use of GIS has made it possible to create spatial models designed to support various public policies, making it easier to understand this phenomenon as well as the possibility to analyze in detail the distribution of different types of cancer. Therefore, Geographic Information Systems allow users to develop and then analyze spatial models for a better understanding of the relationship between cancer, environmental factors and socioeconomic factors [6], [7], [8], [9], [10]. The spatialization of medical data has brought 
more knowledge and helped to understand the determinants from a new perspective, being a defining element in the effectiveness of public policies for preventing, combating and treating cancer and implicitly oncological mortality [11], [12], [13], [14].

Studying the specialized literature, a common element is observed, the lack of relevant data at a detailed level represents an impediment, considering the current situation, a huge volume of medical data. It is necessary to use methods of spatial representation, these offering a broader vision on the distribution of cancers at the national level, regional discrimination, the evolution of cancers, etc.

\section{RESEARCH METHODOLOGY}

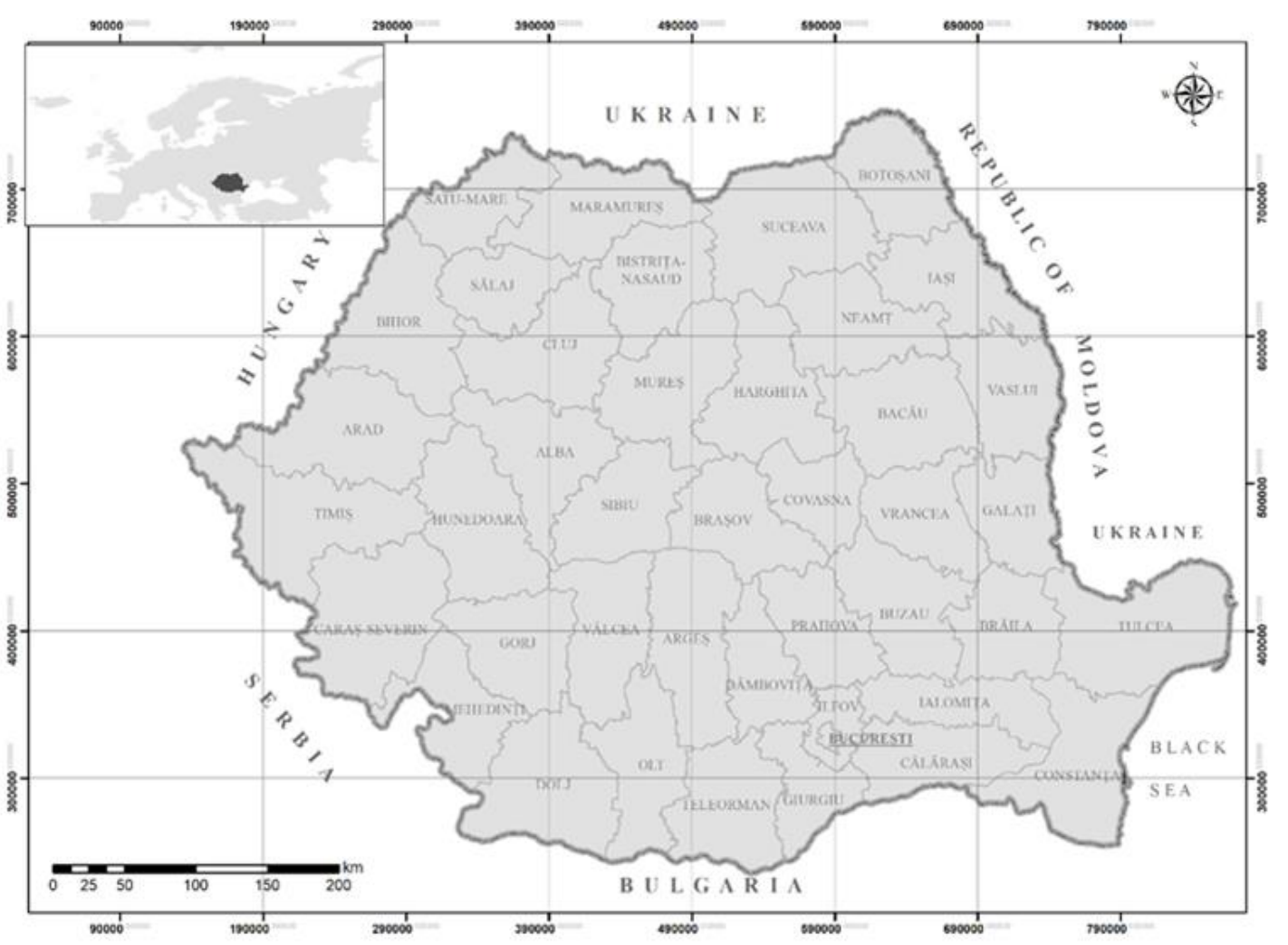

Figure 1. Study area

For this study, we used a database with national coverage, at the level of territorial administrative unit for the period 2008-2017. This database includes the cancer situation in Romania at locality level for each type of cancer, as well as the oncological mortality situation (fig. No. 1).

Based on initial medical data, the prevalence of oncological mortality for category C00C95 was calculated based on the total number. The processing of medical data involved the aggregation of all types of cancer at the locality level that will be spatialized and represented on the map using a GIS tool. To begin with, a relational database system RDBMS - PostgreSQL was used to be able to generate a database with a vast number of records. An important thing to mention refers to the reduced processing time in, the operation of aggregation and later pivoting of the data necessary to obtain statistical situations is improved, it differs depending on the hardware configuration on which these processes are performed. The data were structured in tabular form and were exported in Microsoft Excel compatible format for various statistical situations and specific graphics. These tables were later used to spatialize the oncological mortality using an open source 
software, QuantumGis, through which we connected to the database to assign to each locality the corresponding values, based on a common element, the locality code. These tables once entered in QuantumGis were classified in 5 intervals and represented cartographically in gray tones, the high values with light tones, towards white, and the low values with dark tones, towards black. Thus, oncological mortality was represented according to the total number of cases, the number of cases corresponding to the total population in the form of spatial models for each year, specific to the period 2008-2016

\section{RESULTS}

\section{Oncological mortality in Romania for the period 2008-2016}

The next nine figures (from fig. no. 2 to fig no. 10) represent the situation of the geographical distribution of oncological mortality, how many people died due to one or more types of cancer, and the analysis was performed for the period 2008-2016 according to the total number of deaths.

Analyzing both the spatialization of the phenomenon in the form of spatial models and the database, we can present some concrete situations regarding the intensity of the phenomenon. Therefore, in the nine figures, the geographical distribution of oncological mortality (C00-C96) for total persons highlights the extreme values of over 401 deaths per year, reported to the territorial administrative unit. Cluj Napoca registered in 2008 about 800 deaths, and in 2016 the number increases to 958; another locality with extreme values is Iași, where the number of deaths increases from 700 to 1000 cases, the same happens with the other localities represented in white, they register extreme values of over 401 cases of deaths. The capital of the country, Bucharest ranks 11th as the number of deaths, increasing sharply (from 460 to 742). The low values are found in localities such as Izvoarele in Dolj County, Chirnogi, Călărași County. Greaca Giurgiu county etc. All these localities keep their values below 50 cases of death.



Figure 2. Geographical distribution of oncological mortality (C00-C96) total (persons) year 2008. Source: Ministry of Health 


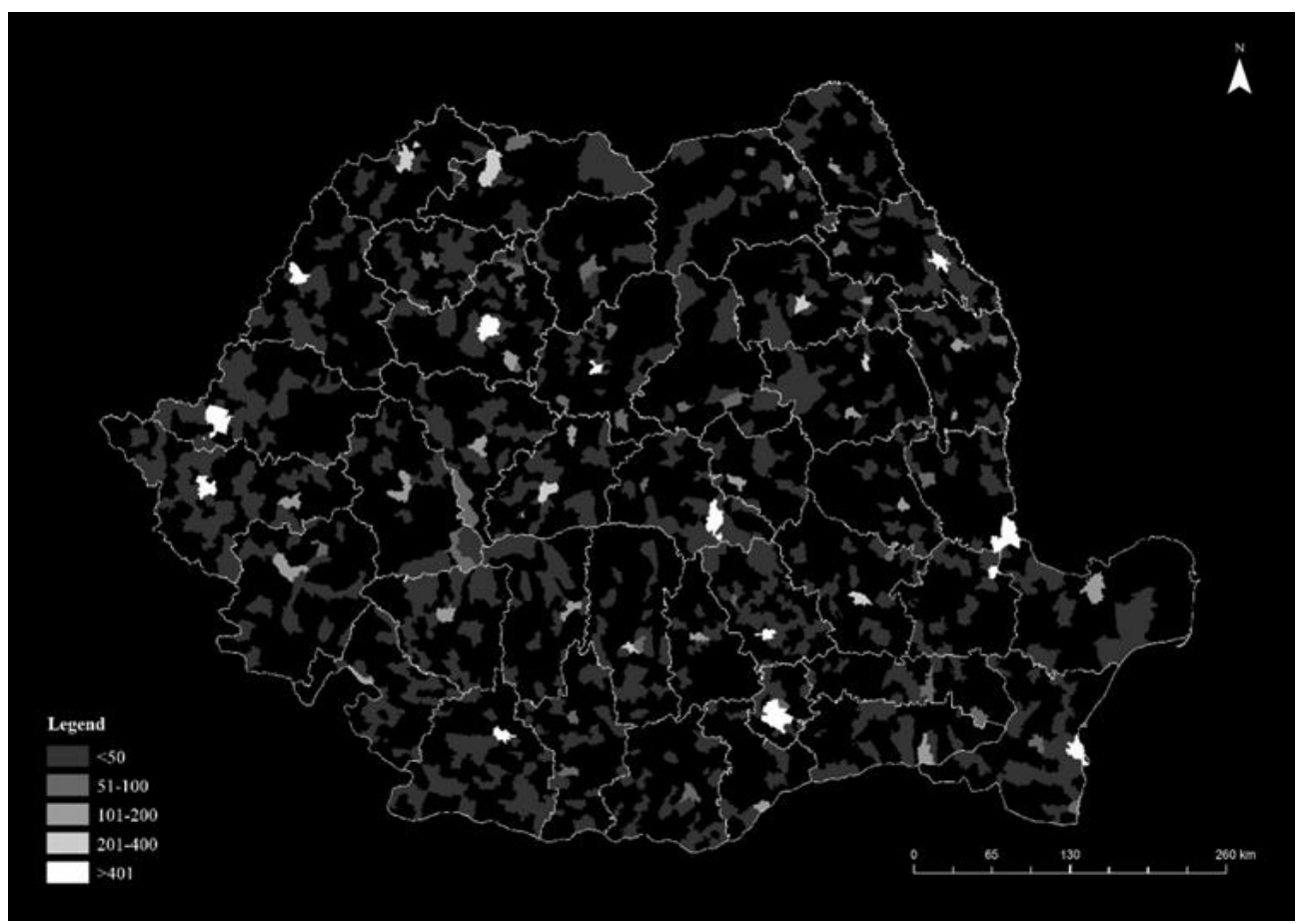

Figure.3. Geographical distribution of oncological mortality (C00-C96) -total (persons) year 2009. Source: Ministry of Health

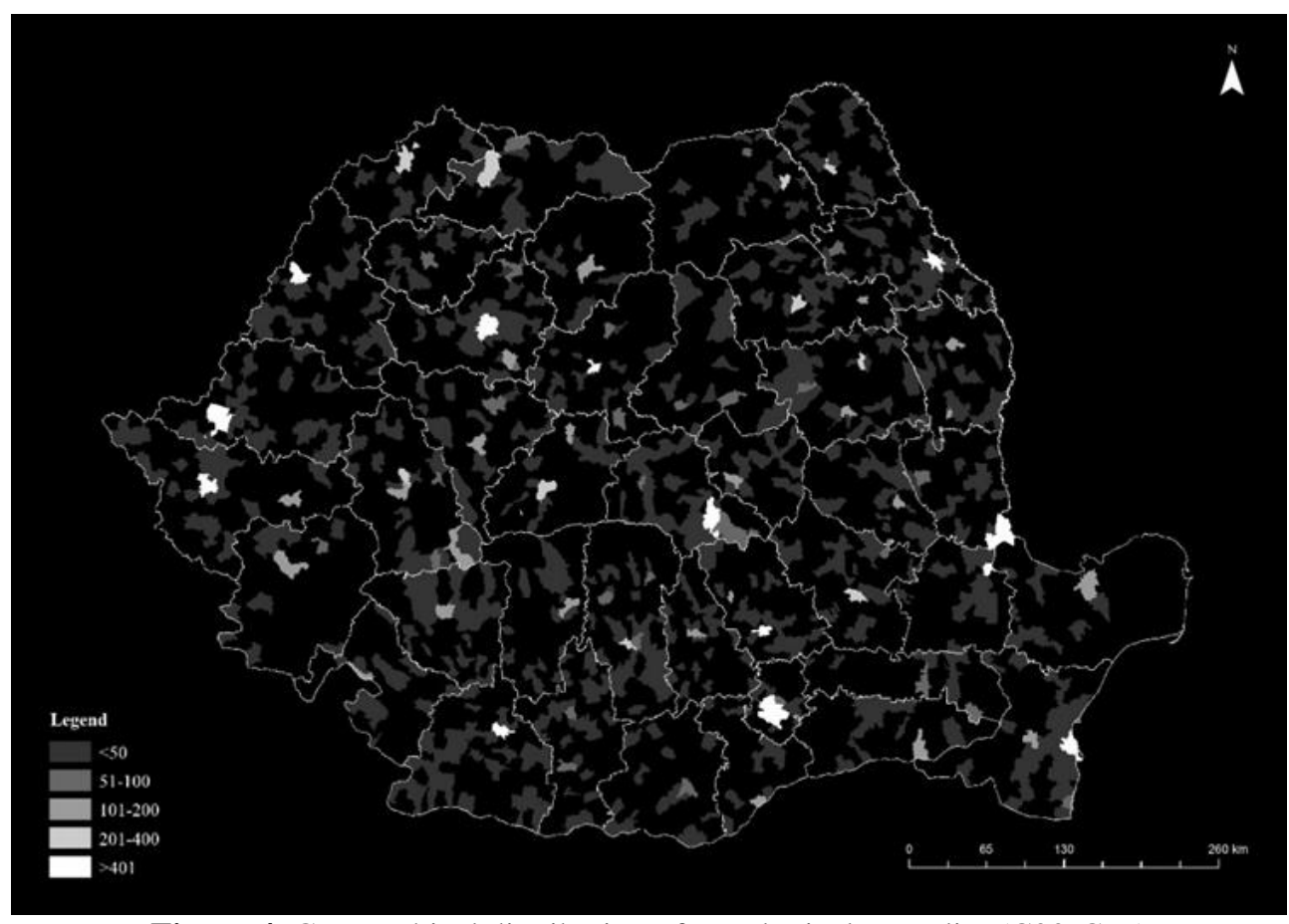

Figure 4. Geographical distribution of oncological mortality (C00-C96) -total (persons) year 2010. Source: Ministry of Health 




Figure 5. Geographical distribution of oncological mortality (C00-C96) -total (persons) year 2011. Source: Ministry of Health



Figure 6. Geographical distribution of oncological mortality (C00-C96) -total (persons) year 2012. Source: Ministry of Health 


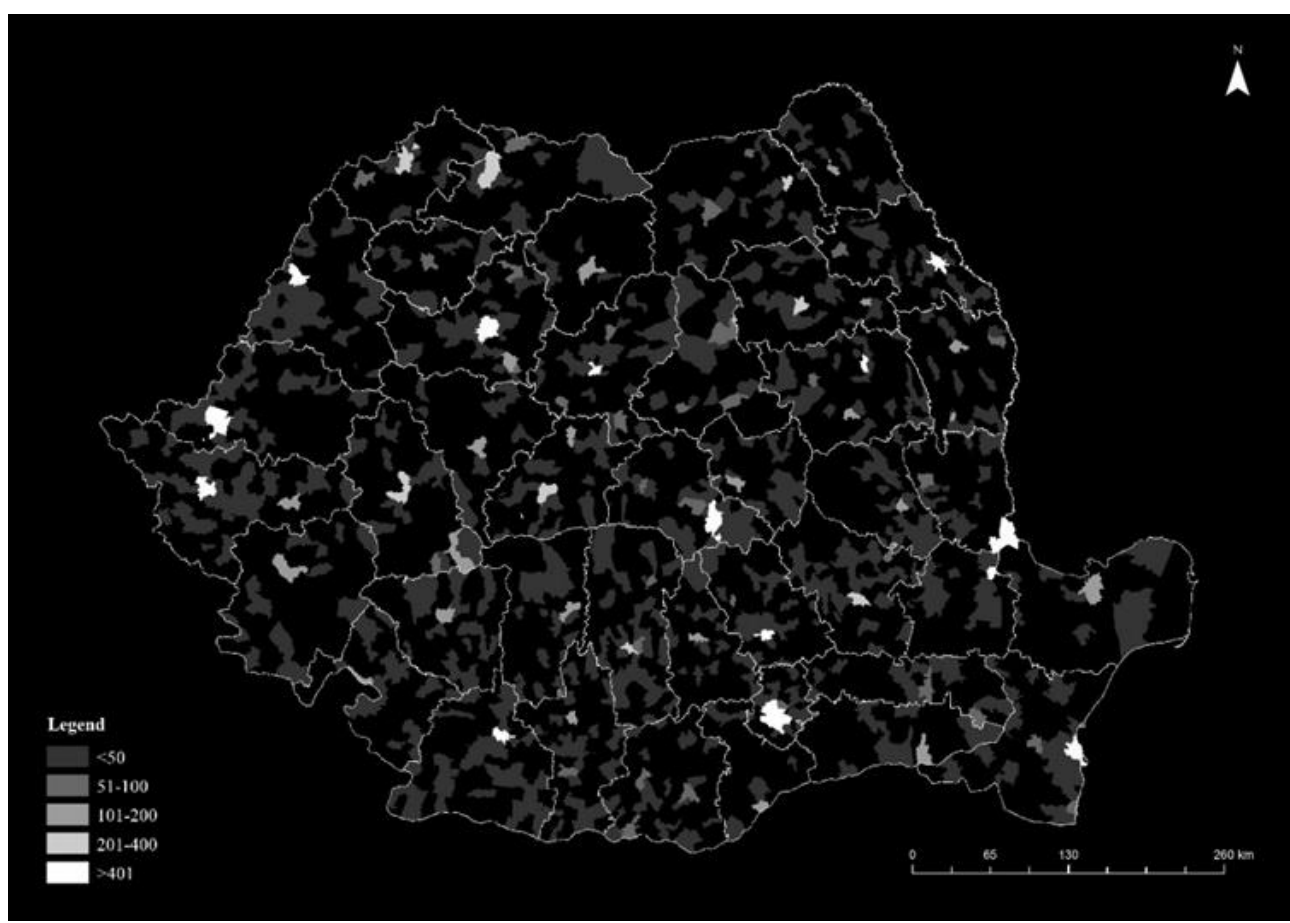

Figure 7. Geographical distribution of oncological mortality (C00-C96) -total (persons) year 2013. Source: Ministry of Health

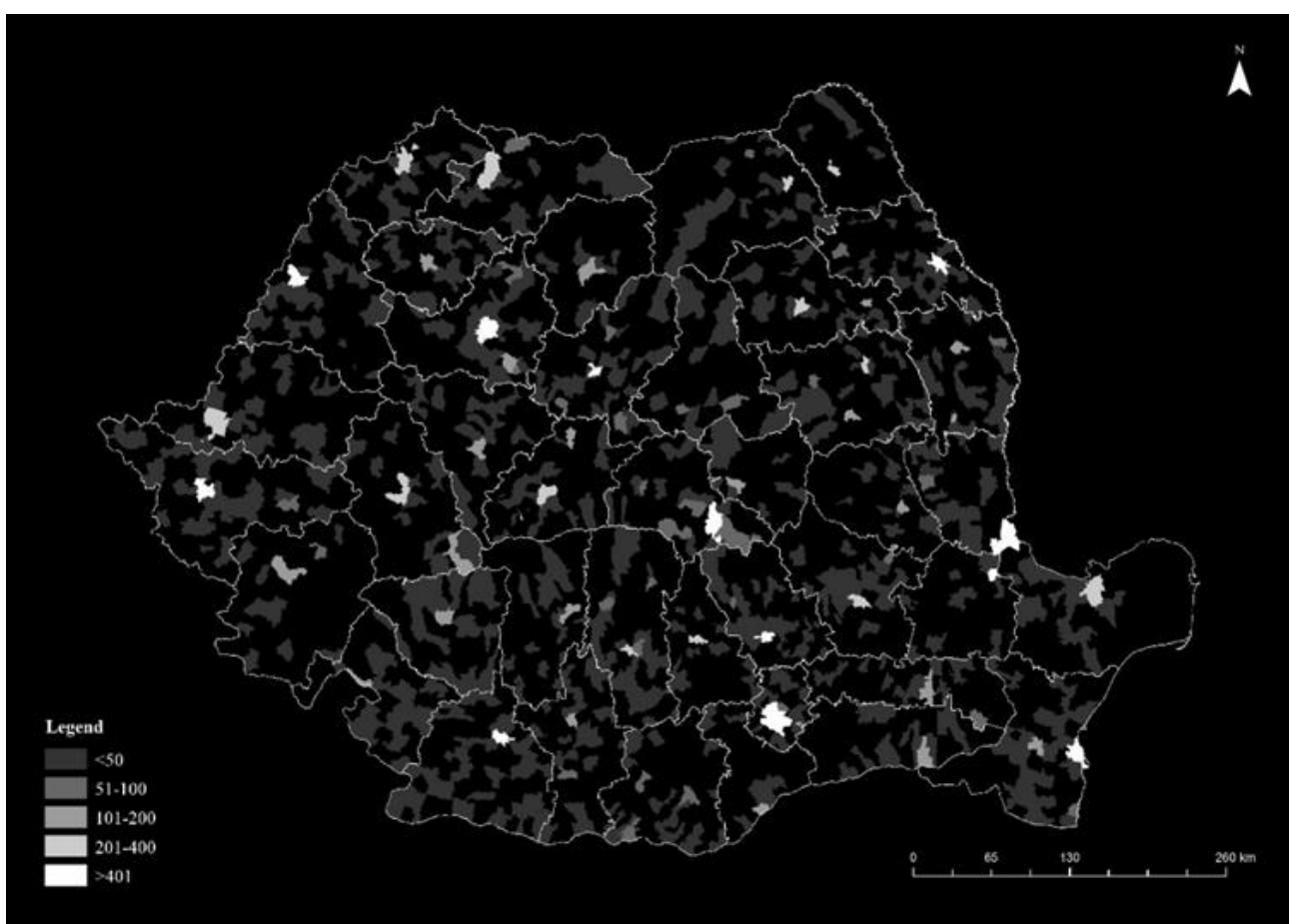

Figure 8. Geographical distribution of oncological mortality (C00-C96) -total (persons) year 2014. Source: Ministry of Health 


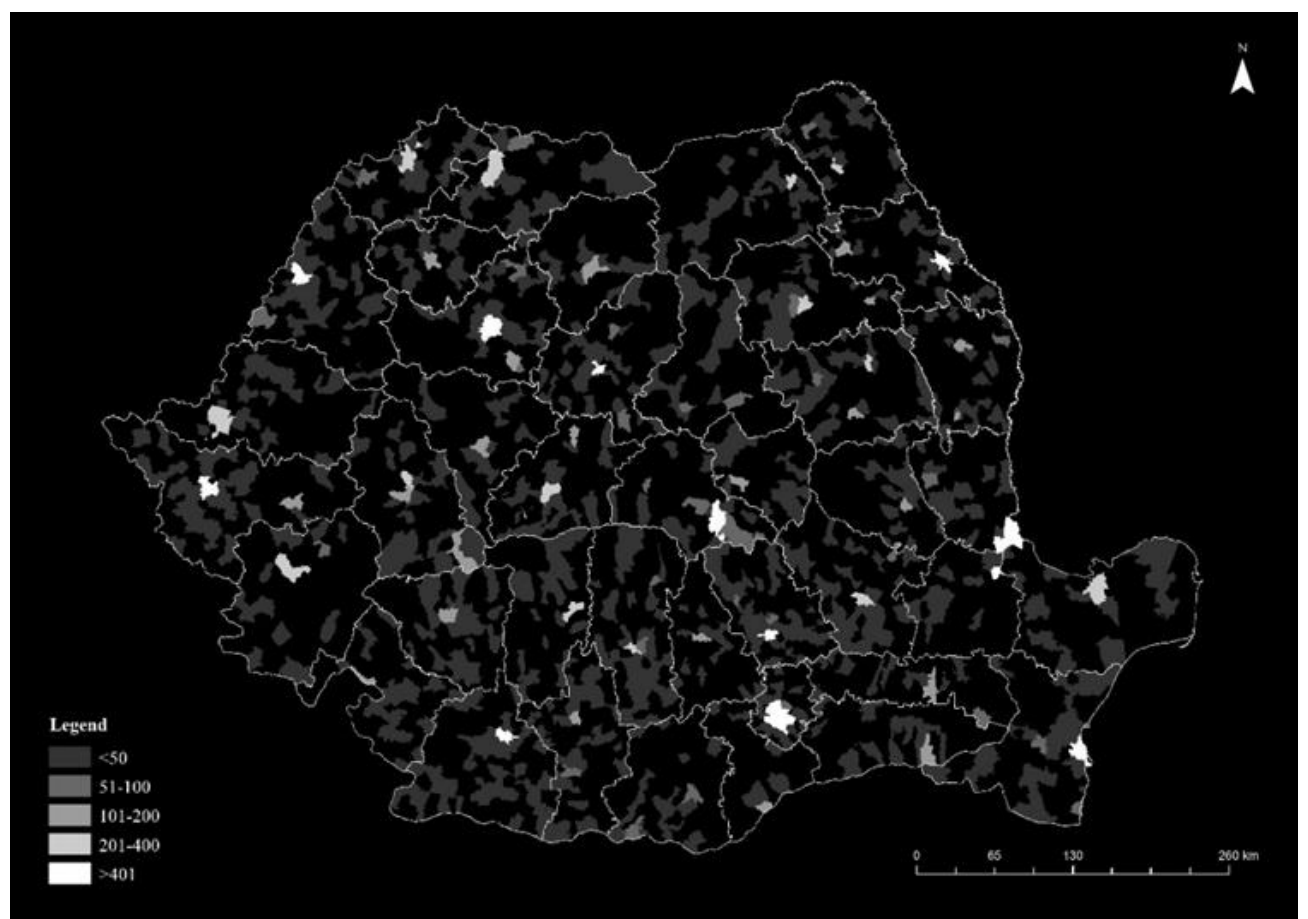

Figure 9. Geographical distribution of oncological mortality (C00-C96) -total (persons) year 2015. Source: Ministry of Health

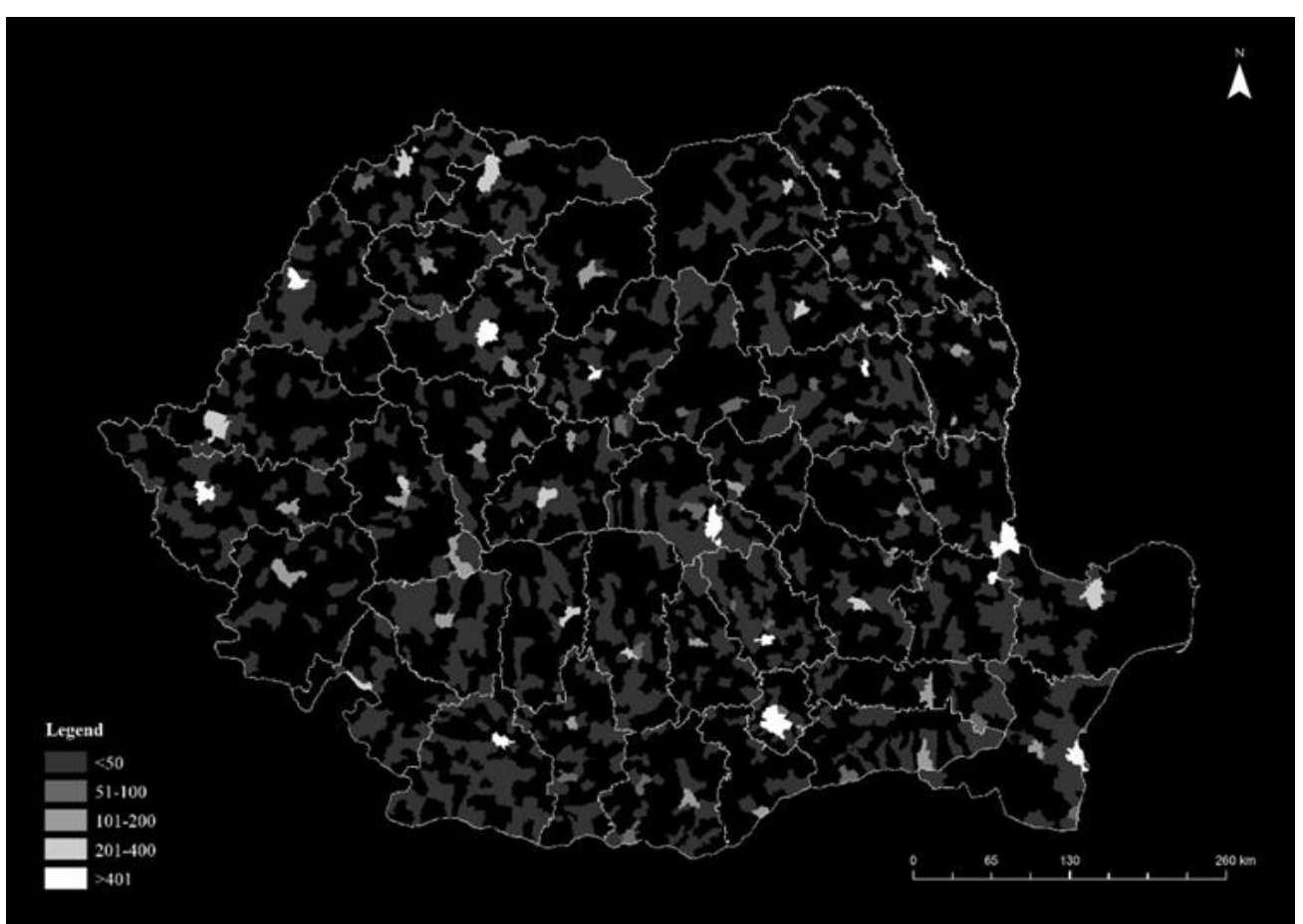

Figure 10. Geographical distribution of oncological mortality (C00-C96) -total (persons) year 2016. Source: Ministry of Health

\section{CONCLUSIONS}

In order to achieve the most relevant results, with the help of geographical information systems, it is necessary to treat together the three main components, the geospatial component, the environmental component and the medical component. It is expected that the maximum values will be found in large urban centers and the minimum values in 
isolated, sparsely populated localities, but this material wants to bring forward the current situation we face, being a starting point for future more detailed studies. What is certain is that the appearance and development of certain carcinogenic diseases that later, in some cases lead to death are closely related to the activities of large urban centers, but also large industrial areas of the country, through huge amounts of pollutants emitted during periods when operating at full capacity

\section{DISCUSSIONS}

Regarding the cancer situation in Romania, the incidence and mortality are increasing, cancer being the second cause of disease, respectively mortality, tending to overcome cardiovascular diseases. Compared to the average incidence and mortality encountered in European countries, the one in Romania exceeds it, for example cervical cancer exceeds 3 times the European average. Another significant example is the cancer found especially in the male population, lung cancer whose average is $10 \%$ higher than in the European Union. The cancers with the most records identified in 2012 for the male population are lung cancer, colorectal cancer and prostate cancer, and among the female population are breast cancer, colorectal cancer and uterine cancer [15], [16]. The situation at national level is complex, in the last 20 years all these values have an upward trend, both in terms of incidence and cancer mortality.

Prevention remains the main way to lead to the lowest possible mortality rate, more precisely the public policies for prevention correlated with the spatial dimension. An example of this is a study conducted in Virginia, USA, which showed a higher rate of cervical cancer mortality in the West where Pap smears were not performed. Thus, a geographic information system was used to spatialize this information, which further helped to develop public policies to finance these annual screening analyzes, leading to a lower rate [17].

\section{REFERENCES}

[1] World Health Organization 2018 https://www.who.int/.

[2] Oh, W. S., Yoon, S., Noh, J., Sohn, J., Kim, C., Heo, J., Geographical variations and influential factors in prevalence of cardiometabolic diseases in South Korea, PLoS ONE, 2018.

[3] Al-Ahmadi, K., Al-Zahrani, A. Spatial autocorrelation of cancer incidence in Saudi Arabia, International Journal of Environmental Research and Public Health, pp 7207-7228, 2013.

[4] Glass, G. E., Schwartz, B. S., Morgan, J. M., Johnson, D. T., Noy, P. M., Israel, E. Environmental risk factors for lyme disease identified with geographic information systems, American Journal of Public Health, pp 944-948, 1995.

[5] Xu, M., Cao, C., Wang, D., Kan, B., Xu, Y., Ni, X., Zhu, Z. C. Environmental factor analysis of cholera in China using remote sensing and geographical information systems, Epidemiol \& Infection, pp 940-95, 2016.

[6] National Institute of Environmental Health Sciences (https://www.niehs.nih.gov/).

[7] Hay, S. I., George, D. B., Moyes, C.L., Brownstein, J. S. Big data opportunities for global infectious disease surveillance, PLoS Medicine, 2013.

[8] Ferlay, J., Partensky, C., Bray, F. More deaths from pancreatic cancer than breast cancer in the EU by 2017. Acta Oncologica, pp 1158-1160, 2016.

[9] Jemal, A., Bray, F., Center, M. M., Ferlay, J., Ward, E., Forman, D. Global cancer statistics, CA A Cancer Journal for Clinicians , pp 69-90, 2016. 
[10] Brewer, C. A. Basic Mapping Principles for Visualizing Cancer Data Using Geographic Information Systems (GIS). American Journal of Preventive Medicine, 2006.

[11]Jones, L., Chilton, J., Hajek, R., Iammarino, N., Laufman, L. Between and within: international perspectives on cancer and health disparities, Journal of Clinical Oncology, pp 2204-2208, 2006.

[12] Rainey, J. J., Omenah, D., Sumba, P. O., Moormann, A. M., Rochford, R., Wilson, M. L. Spatial clustering of endemic Burkitt's lymphoma in high-risk regions of Kenya, International Journal of Cancer, pp 121-127, 2007.

[13] Mosavi-Jarrahi, A., Moini, M., Mohagheghi, M.-A., Alebouyeh, M., Yazdizadeh, B., Shahabian, A., Nahvijo, A., Alizadeh, R. Clustering of childhood cancer in the inner city of Tehran metropolitan area: a GIS-based analysis, International Journal of Hygiene and Environmental Health, pp 113-119, 2007.

[14] Siegel, R. L., Miller, K. D., Jemal, A.Cancer statistics, 2016 CA: Cancer Journal for Clinicians, pp 7-30, 2016.

[15] Romania Functional Review HEALTH SECTOR Final Report Public Disclosure Authorized.

[16] National Institute of Statistics, Death by causes in Romania, 2015.

[17] https://www.livestories.com/statistics/virginia/cancer-deaths-mortality. 